\title{
De estigmas e injurias: cuando las prácticas discriminatorias se hacen presentes de forma cotidiana en la vida de las personas en situación de calle
}

\section{Of stigmas and insults: when discriminatory practices become part of the daily life of Street-people}

Mariana Biaggio ${ }^{1}$

Aceptación: 21 agosto 2009

Aprobación: 4 abril 2010

\section{RESUMEN}

A partir de 1997 el Gobierno de la Ciudad de Buenos Aires (GCBA) comenzó a implementar diversos programas sociales destinados a la atención de la "emergencia habitacional" en la Ciudad de Buenos Aires, interpelando a un nuevo sujeto "merecedor" de estas políticas: las personas en situación de calle. Estos programas se encuentran hoy agrupados en la Dirección General de Atención Inmediata (DGDAl) del Ministerio de Desarrollo Social del GCBA. Se trata de una política que se enmarca en un proceso que profundiza la focalización, puesto que su objeto de intervención son los más pobres entre los pobres. El derecho a la asistencia, en este sentido, deriva de las condiciones de exclusión. Estos grupos "vulnerables" a partir de su condición de pobreza extrema -certificada con un "diagnóstico social" de "persona en situación de calle"-pueden pasar a integrar la población a la que está dirigida la política asistencial de la DGDAI.

Teniendo en cuenta este marco, nos proponemos realizar un análisis etnográfico acerca de las formas en que la discriminación y la exclusión se hacen presentes en la vida cotidiana de las personas que para utilizar estos programas sociales deben dar cuenta de una posición de exclusión, de la cual deriva el derecho a la asistencia. Nos interesa identificar y analizar las prácticas discriminatorias a las que están expuestos los "beneficiarios" de los programas destinados a atender la "emergencia habitacional" en la Ciudad de Buenos Aires.

Palabras clave: Prácticas discriminatorias, estigmas, injurias, personas en situación de calle.

\section{ABSTRACT}

From 1997, the Government of the Autonomous City of Buenos Aires (GCBA) began to implement different social programs to assist the "housing emergency" in the city of Buenos Aires by questioning the new subject "worthy" of these policies: people in a street situation. Today, these programs are grouped in the General Direction of Immediate Attention (DGAI) belonging to the GCBA's Social Development Department. This policy is kept within the boundaries of a process that gets inside focalization, as its object of intervention are the poorest among the poorest. The right to assistance, in this sense, derives from the conditions of exclusion. These "vulnerable" groups due to their extreme poverty -certified by a "social diagnosis" of "person in street situation"- can start to be part of the population to which the DGAl assistance policy is directed.

Taking this framework into account, we intend to make an ethnographic analysis of the ways in which discrimination and exclusion are present in the daily lives of those people who in order to make use of these social programs have to account for an exclusion position, which derives from the right to assistance. We are interested in identifying and analyzing the discriminatory practices to which the "beneficiaries" of programs meant to assist the "housing emergency" in the City of Buenos Aires are exposed.

Key words: Discriminatory practices, stigmas, insults, street people.

Doctoranda en Ciencias Sociales, Instituto de Investigaciones Gino Germani, Facultad de Ciencias Sociales, Universidad de Buenos Aires. Becaria Conicet. marianabiaggio@yahoo.com.ar 


\section{Introducción}

En el año 1997, en su primer trabajo estadístico vinculado a los sin techo, el Gobierno de la Ciudad de Buenos Aires (GCBA) contabilizó 1.085 personas en situación de calle. El último conteo ocular realizado en el 2009 informó un total de 1.950 personas. Sin embargo, en contraste con las cifras oficiales, Proyecto $7^{2}$ estima que son 4.000 las personas en esa situación, a diferencia de Médicos del Mundo, que incluyendo en sus estadísticas a inquilinos de hoteles/pensión y ocupantes de inmuebles, estima que son 10.000 las personas cercanas a la calle en la Ciudad de Buenos Aires. Al momento, éstas son las únicas cifras con las que contamos. Desconocemos la forma en que las ONG produjeron aquellos datos, pero en el caso del GCBA - a partir de nuestra participación en dos conteos oculares (2004 y 2005)- podemos afirmar que esas cifras no son del todo confiables.

De todas formas, esas alarmantes cifras nada nos dicen acerca de cómo viven las personas que cotidianamente enfrentan al hambre, la salud y el descanso como problemas que necesitan resolver: ¿cómo logra vestirse, asearse y comer quien no tiene salario?, ¿de dónde provienen los mínimos ingresos monetarios que obtienen? Preguntas que despiertan la curiosidad de muchas personas (en términos de nuestros entrevistados) del otro lado de la calle. Sin embargo, a partir de nuestro trabajo de campo, pudimos compartir diferentes momentos con los residentes de un parador del GCBA (institución donde pueden dormir, bañarse y comer) y participamos de los ensayos de un coro de ensambles vocales conformado por personas albergadas en hogares y paradores del GCBA. Allí, fuimos testigos de sus preocupaciones, las que se vinculan con el maltrato, la discriminación y el prejuicio presentes en las relaciones interpersonales. Maltrato, discriminación y prejuicio que se constituyen en objeto de molestia y dolor, pero también en causas de bromas que fortalecen el humor. Si por un lado fuimos testigos del dolor que genera la discriminación presente en las relaciones personales, por otro, también atendimos a la forma en que algunas de esas relaciones permiten la construcción de bromas, así como también la resolución de las necesidades llamadas "básicas" por los estudios de pobreza. Nos preguntamos entonces ¿cómo podríamos caracterizar a las relaciones que día a día construyen las personas en situación de calle?

Esta pregunta nos guiará en el presente trabajo, en el que nos proponemos realizar un análisis etnográfico acerca de las formas en que la discriminación y la exclusión se hacen presentes en la vida cotidiana de las personas que están en calle y que son albergadas por el GCBA. El estigma y la injuria serán temas centrales a analizar porque forman parte de las relaciones discriminatorias construidas por y hacia las personas en situación de calle, colaborando en la profundización de procesos estigmatizantes.

En primer lugar reseñaremos la forma en que este tema comenzó a hacerse visible. Luego describiremos el inicio de la intervención del Estado en este problema, a partir de la despenalización del vagabundeo, detallando los planes sociales a los que pueden acceder las personas que están en calle. La creación de estos planes amplió los recursos que ya proveían distintas instituciones de la Iglesia dependientes de Caritas y de la red SIPAM (Sistema Interparroquial de Ayuda Mutua), los que conforman distintos puntos de los circuitos recorridos por las personas. Haremos referencia a las dificultades con las que se encuentran quienes quieren ingresar a estas instituciones, momento en que deben necesariamente relacionarse con otro para poder hacer uso de los recursos incluidos en los planes y programas, por los que así podrían pasar a ser reconocidos como asistidos o beneficiarios.

Este será el contexto que permitirá dar a conocer algunos aspectos que conforman la cotidianeidad en la cual las personas en situación de calle construyen relaciones con sus pares, con profesionales y administrativos del Ministerio de Desarrollo Social del GCBA y con el resto de la sociedad. Y será este el punto principal en el que nos detendremos, siendo el objetivo de este trabajo describir y analizar, desde el punto de vista de nuestros

\footnotetext{
"Proyecto 7. Gente en situación de calle" es una Asociación Civil conformada por un conjunto de personas que han padecido la situación de calle, por otras que aún siguen padeciéndola, por profesionales y por estudiantes, quienes se proponen incidir en políticas que propicien una mejor calidad de vida y dignificación de los ciudadanos/as en calle.
} 
entrevistados, las diversas formas que adquieren aquellas relaciones, atravesadas por el estigma, la injuria y la discriminación.

El presente, es un avance del análisis de las observaciones efectuadas y de las entrevistas tomadas hasta el momento, en el marco de la realización del trabajo de campo para mi tesis doctoral. En ese sentido, constituye un análisis preliminar. Las observaciones y las entrevistas fueron realizadas en el parador Bepo Ghezzi del GCBA y en el Centro Cultural Plaza Defensa, espacio donde se realizaban los ensayos del coro conformado por residentes de hogares y paradores. De este modo, las conclusiones a las que podamos arribar, de ninguna manera podrían ser generalizables a las personas que habitan en las calles de la ciudad, siendo solamente representativas de los puntos de vista de nuestros entrevistados: personas albergadas en hogares y paradores nocturnos del GCBA, clasificadas como "personas en situación de calle". Destacaremos en itálicas los términos nativos y agregaremos a ellos las comillas cuando se trate de una cita textual.

El inicio de un proceso de visibilización de las personas en situación de calle.

En el año 1997, por primera vez, la problemática del "sinhogarismo" ingresó en la agenda pública del GCBA como problema social a atender, y para ello la primera acción emprendida fue la medición de este problema, su cuantificación. El trabajo estadístico relativo a la cuantificación de la problemática de las personas en situación de calle consistió y consiste actualmente en un conteo ocular que se desarrolla una vez por año. Se trata de operativos en los cuales durante una noche profesionales del Ministerio de Desarrollo Social del GCBA (de aquí en adelante Desarrollo Social, como suelen referirse a este ministerio nuestros entrevistados) se dedican a contar personas en calle, en base a lo que logran ver durante la noche y desde móviles con los que recorren la ciudad. La metodología consiste en dividir a los profesionales en 20 equipos. Cada uno tiene a su cargo un recorrido o circuito ${ }^{3}$. Los 20 circuitos abarcan todo el ámbito geográfico de la ciudad. Los profesionales deben "detectar" personas en situación de calle, y su diferenciación por sexo y edad, a partir de la apariencia física. En un documento donde el GCBA presenta los resultados del cuarto conteo $(2002)^{4}$ explicita, en sus consideraciones metodológicas, las "dificultades en la demarcación del universo, ya que se trata de personas en situación de transitoriedad geográfica y temporal". Por ello, el documento recomienda tener en cuenta

"los distintos circuitos de mayor frecuencia y lugares de 'refugio' de las personas sin techo. Las distintas plazas, avenidas, calles laterales, paseos comerciales, hospitales, bocas de subte, parques de la ciudad, iglesias y parroquias con comedores, como así también los ámbitos céntricos, donde espontáneamente se reúnen las personas sin techo, debido a la disponibilidad de recursos de subsistencia que brindan los numerosos negocios e instituciones que allí funcionan (dádivas, alimentos, changas, el cuidado de vehículos y proce. samiento de residuos)".

Más adelante, explica la forma en que deberá recabarse la información, detallando la experiencia del año 2002:

"Modalidad de recolección de datos: La recolección de la información se realizó en forma visual en la modalidad de conteo, sin establecer contacto con la población. Se utilizó una planilla que recababa los siguientes datos:

- Lugar de detección

- Sexo

- Grupo etário aproximado

- Forma de agrupamiento (personas solas o presuntamente integradas en familias)

- Tipo y cantidad de pertenencias

- Estado de la indumentaria y del aseo personal".

El término circuito también es utilizado por los beneficiarios, pero con un sentido diferente. A él nos referiremos en el apartado siguiente.

4 Ese documento, realizado por el Programa Buenos Aires Presente, fue entregado a los profesionales que participamos del conteo del año 2004. Allí se detallan los antecedente del $4^{\circ}$ conteo (año 2002), sus resultados y las consideraciones metodológicas. 
En estas citas puede apreciarse el grado de subjetividad de los resultados de estos conteos y su reconocimiento por parte del organismo que los lleva adelante. En los conteos de los que participé (2004 y 2005), no agregaron a las cifras obtenidas por ese medio a las personas que en la noche del conteo estaban alojadas en hogares y en paradores de la ciudad, lo que disminuye de una manera considerable sus resultados ${ }^{5}$.

Coincide la incorporación de este tema en la agenda de gobierno con el aumento en los niveles de desempleo, subempleo, el consecuente incremento de la pobreza y la indigencia durante la década de los 90 y también con el fallecimiento, a fines de marzo del año 1997, de una persona sin techo en las calles de la ciudad, noticia que tomó importante relevancia pública a través de los medios masivos de comunicación (Boy, 2007). Por su parte, los edictos policiales ${ }^{6}$ que penaban la mendicidad y el vagabundeo, habían sido suspendidos en 1996 a partir de la convención constituyente que daría lugar, en el año 1998, a la creación del Código Contravencional de la Ciudad, o Código de Convivencia Urbana. El vagabundeo, entonces, no solo había dejado de ser considerado delito, sino que se tornaba en un problema "merecedor" de asistencia social pública.

Por su parte, P. Malanca y M. S. Repetto, ex coordinadoras del $\mathrm{BAP}^{7}$, señalan en un trabajo del año 2003, que el fenómeno se hizo visiblemente masivo y notable en las calles de la ciudad de Buenos Aires en el año 1996. La magnitud del problema y las cifras "producen un impacto permanente sobre el imaginario popular del vecino de la ciudad quien, hasta la aparición de este fenómeno, no estaba acostumbrado a toparse con la escena más dramática de la pobreza en la punta de su pie y a la vera de su vista. La pobreza estaba socializada en los bolsones de pobreza consensuados: la villa, pero no a la vista de todos" (Repetto y Malanca, 2003. El destacado es mío).

Es decir, que la magnitud del problema -el incremento de las personas en calle- vinculado con el hecho de que el mismo se hubiera hecho visible -ya no circunscripta ciertas áreas urbanas- fueron factores que intervinieron a la hora de que el gobierno definiera "tomar manos en el asunto". De hecho, uno de los primeros programas creados, el BAP, recibía en su mayoría llamados de vecinos (como llaman las ex coordinadoras del BAP y la actual gestión del gobierno porteño a las personas que no están en situación de calle) preocupados o con interés en presentar quejas por los sin techo cercanos a sus domicilios. En los primeros meses del año 2002 solo el 20\% de las llamadas que recibió aquel programa se correspondieron a demanda de tipo espontánea (Repetto y Malanca, 2003). Eran entonces los vecinos, y no las personas en calle, quienes parecían urgidos de que el GCBA hiciera algo por estas personas.

El hecho de que el problema se hiciera visible, la ruptura con el acuerdo tácito de que la pobreza tenía "su lugar" en las villas o en los llamados "bolsones de pobreza", las quejas de los vecinos de la ciudad, el fallecimiento de una persona en la calle que conmovió públicamente y se transformó en noticia trascendente, fueron diversas miradas de un mismo problema que necesariamente requería que el gobierno interviniera.

El GCBA decide "intervenir": creación de los programas, ampliación de los circuitos

Luego del relevamiento estadístico y de la despenalización del vagabundeo, en el año 1997 el GCBA creó por medio del decre-

Considerando solamente a los dos paradores nocturnos del GCBA para hombres adultos, a las cifras obtenidas deberían agregarse aproximadamente 220 personas.

6 El decreto 17.189/56, firmado por el presidente Aramburu, ratificado por la Ley 14.467, reguló la convivencia de los porteños durante más de 40 años por medio de los edictos policiales. Los edictos fueron normas polémicas porque al detener, interrogar o penar (con multas o arrestos) no actuaba la Justicia sino la Policía Federal.

7 Buenos Aires Presente es un programa del GCBA que acerca alimentos, abrigo, y brinda asistencia sanitaria y psicológica a las personas que viven en la calle o que atraviesan una situación de "riesgo social", por medio de equipos integrados por profesionales que se desplazan en unidades móviles por la ciudad, trasladando la prestación al lugar donde es requerida. Funciona también como un articulador de gestión, ya que la gente atendida por el BAP es derivada a distintos servicios y programas. Extraído de la página del GCBA: http://www.buenosaires.gov.ar/areas/des_social/bap/?menu_id=151. Recuperado en mayo 2008. 
to $607 / 997$ el primer programa: "Programa para las Personas sin Techo". Hoy en día sigue funcionando, teniendo a su disposición varios hogares (espacios de albergue) donde las personas pueden dormir, asearse y cenar. Dos años más tarde, en 1999, por medio del decreto 2.018 el gobierno creó el BAP, que cuenta con móviles donde los profesionales se desplazan para atender la emergencia en la calle y disponía también de una central telefónica (que es hoy un programa independiente, llamado 108). Los dos primeros paradores fueron creados en el 2003, los que albergan por una noche a tantas personas como capacidad tengan las instituciones ${ }^{8}$, a diferencia de los hogares en los cuales las vacantes (en vez de ser de duración diaria) tienen una duración de varios meses o años. A los paradores las personas pueden acceder tantas veces como lo requieran, en forma inmediata, y cada vez su vacante durará solo por la noche en la que se presenta. En cambio a los hogares las personas ingresan con derivaciones y luego de una entrevista de admisión. Allí tienen reservada su vacante durante meses o años, pero, una vez expulsados o "egresados" es muy difícil que puedan reingresar. En el 2006 el GCBA creó la línea 108, tomando a su cargo la función de recepción telefónica que hasta entonces tenía el BAP. Es una línea telefónica de emergencia social desde donde se derivan las situaciones planteadas hacia el programa pertinente, en su mayoría el BAP. Y ese mismo año el programa que ofrece un subsidio habitacional amplió su cobertura dejando de asistir exclusivamente a familias, e incorporando también a "personas solas en situación de calle" (artículo 4 decreto 690/06).

Como podemos ver, a partir del año 1997 fueron variados los decretos que crearon diversos programas que se incluyen actualmente en los circuitos que marcan la cotidianeidad de las personas en calle. Los programas estuvieron inicialmente destinados a los "sin techo", pero a partir del 2003 encontramos las primeras referencias a las "personas en situación de calle". En el Documento 28 del Centro de Documentación en Políticas Sociales del GCBA (2003) encontramos alternadamente la referencia a ambas nominaciones. En el 2006 el GCBA hace a un lado la anterior referencia al "sin techo" y define a las "familias o personas solas en situación de calle, entendiendo por tal a aquellas que se encuentran en inminente situación de desamparo habitacional, o se hallen transitoriamente sin vivienda o refugio por causa de desalojo u otras causas" (Art. 4 decreto $690 / 06$ ).

En nuestro inicio de trabajo de campo, en el año 2004, esta última nominación era utilizada por los profesionales y directivos y no por los beneficiarios. Sin embargo, a partir de 2006 comenzamos a encontrar su uso incluso por parte de algunas de las personas así clasificadas, quienes utilizan actualmente ese término para referirse a sí mismas o para bautizar a la organización colectiva a la que pertenecen, como la del Movimiento Independiente de Personas en Situación de Calle ${ }^{9}$. Las personas en situación de calle pasaron a ser un actor en proceso de visibilización y reconocimiento como sujeto merecedor de asistencia pública. Este proceso muestra una contrastante diferencia con el observado en el caso de otros actores que permanecen invisibilizados, como el de personas que habitan en hoteles-pensión, inquilinatos, villas miserias e inmuebles ocupados, quienes no cuentan con ingresos suficientes ni garantías que les permitan acceder al mercado formal de vivienda ${ }^{10}$. Para estas categorías de población no existe una denominación particular ni datos certeros o estadísticas oficiales confiables. La falta de números precisos es ejemplo de una lógica selectiva de intervención/no intervención del Estado a través de políticas activas o de su omisión (Rodríguez, 2006: 66). Es así como estos actores permanecen invisibilizados, y ejemplo de ello es que el ingreso de estas

El parador Retiro tiene capacidad para 200 personas por noche y el Bepo Ghezzi de 70.

9 Movimiento Independiente de Personas en Situación de Calle: nace y se nutre de personas que sufren la inestabilidad de la vivienda, abarcando a personas que viven en las calles, alojadas en albergues parroquiales o del Estado, quienes viven en asentamientos, villas, inmuebles ocupados o prestados. Se caracteriza por ser un movimiento independiente que incluye en su hacer política, el ser "facilitadores de trámites" en Desarrollo Social, asesorando de manera informal a las personas que allí concurren. Llevan adelante diferentes emprendimientos productivos que proponen salidas laborales a personas desempleadas.

10 Para más información acerca de este tema ver Natalia Verón (2008), "Sin garantía: Trayectorias sociales y disputas por el espacio urbano. El caso de los Inquilinos Precarios en la Ciudad de Buenos Aires". Presentado en el IX CAAS, Universidad Nacional de Misiones, Argentina. 
personas en algunos de los programas habitacionales de corte transitorio del GCBA, es bajo la denominación de "persona en situación de calle".

Mientras el GCBA actualmente ofrece hogares, paradores, subsidios habitacionales, atención en calle y un ticket social, la Iglesia continúa prestando servicios de comedores, merenderos, roperos y también hogares. Por su parte, organizaciones de la sociedad civil como Arte sin Techo o Fundais, ofrecen talleres, a veces con un subsidio como contraprestación, y Hecho en Bs As y Periódico Diagonal dan la posibilidad de la venta de una revista en calle a cambio de una retribución. Todas ellas, salidas que permiten el rebusque y cierto ingreso monetario que no alcanza para la salida de la calle.

\section{El circuito como círculo vicioso}

Con estos recursos existentes en la ciudad, las personas en situación de calle organizan su cotidianeidad con una rutina que incluye la asistencia a espacios donde poder dormir, comer, vestirse, asearse y participar (en algunos casos) de talleres recreativos o de capacitación. A esta cotidianeidad se refieren con el término de circuito ${ }^{11}$ o círculo vicioso, porque imponiendo horarios según el funcionamiento de los programas de vital importancia para ellos, no deja lugar a la creación de proyectos personales, construyendo y reproduciendo la vida de la calle sin brindar alternativas a ella. El circuito solo facilitaría, en estos términos, la permanencia en calle. "Hay muchos que pasan de un comedor al otro y así están todo el día... buscando dónde está la mejor comida del día". Maximiliano vivó un año en la calle, durante seis meses concurrió a uno de los paradores del GCBA y a finales de 2005 estaba alquilando un departamento en la Ciudad de Buenos Aires y trabajando en un hospital. Me contó acerca de su experiencia en el parador, que "salía con ga- nas de buscar otra cosa, pero terminaba en el circulo vicioso (...) salía, tomaba algo y volvía para hacer la fila (para ingresar al parador) a las dos de la tarde".

$\mathrm{El}$ ingreso a los programas mencionados requieren de cierta formalidad burocrática, que varía de caso en caso, pero que suele incluir entrevistas de admisión, presentación de papeles que justifiquen el discurso y la "historia" contada en la entrevista, certificados médicos en algunos casos, y por supuesto la infaltable constancia de persona en situación de calle $e^{12}$. Cada una de estas instancias presupone tiempo y dedicación para la obtención de estos certificados y de las entrevistas necesarias. Algunos de los programas, como el que ofrece un subsidio habitacional, son difíciles de conseguir por la exigencia en la documentación a presentar, que no se corresponde con la realidad que enfrentan día a día las personas en calle ${ }^{13}$.

En todos los casos son largas las colas que deben hacer en Desarrollo Social, las que incluso pueden comenzar la noche anterior a la entrega de números. El malestar que genera el hacer pública otra vez la desgraciada parte de su historia, es agravado ante la posibilidad de incluir también maltrato del personal y quizás un nuevo rechazo.

A su vez, la organización de los programas suele modificarse, los días de entrega de los tickets pueden variar, las fechas del cobro del subsidio habitacional pueden suspenderse sin previo aviso y sin entrega de algún papel en el que el gobierno se comprometa a pagar. Esto último puede traducirse en que el encargado del hotel, ante la falta de pago, desaloje a la persona y/o cierre con candado la habitación. Modificaciones organizativas que impactan en aspectos trascendentales de la vida de las personas. Las opciones que se presentan ante la pérdida de la habitación varían, abarcando la posibilidad de recibir ayuda de algún amigo o

11 El término circuito no solo es utilizado por los beneficiarios, sino también por los empleados de Desarrollo Social. Por ejemplo en la Ficha de Admisión que completan los profesionales de los paradores pueden observarse varios ítemes: el tercero se denomina "Situación de Calle" y consta de tres áreas a completar tituladas "Reseña", "Circuito" y "Hogares/ Instituciones".

12 El diagnóstico de persona en situación de calle lo realizan en su mayoría los trabajadores sociales. Debe estar presente en las derivaciones, pues es el requisito que habilita y permite el ingreso de la persona a la institución o programa a donde está dirigida la derivación.

13 Entre otros requisitos, para la obtención del subsidio habitacional el GCBA exige dos años de antigüedad comprobables de residencia en la Ciudad de Buenos Aires. Para una persona que duerme en la guardia de un hospital, una plaza o refugio, es muy difícil obtener un documento que compruebe la residencia en la ciudad y mucho menos la antigüedad exigida. 
familiar (en caso de que lo hubiera y en caso de que quien necesita ayuda pudiera aceptarla), volver a la calle, o acudir a un parador (en donde si bien el ingreso es inmediato, en el día y sin trámite previo, exige ciertos requisitos, algunos explicitados en "las condiciones de admisión y permanencia", como por ejemplo no estar bajo el efecto de alguna sustancia ilícita o el alcohol). En este último caso, si acudiera a un parador, cabe entre las opciones que los representantes gubernamentales recuerden que el solicitante había sido subsidiado, motivo que justificaría la denegación de su ingreso. La sospecha de un posible uso indebido del dinero obtenido por un subsidio habitacional (que exige utilizarlo solamente en el alquiler de una vivienda), en la práctica puede ser suficiente para rechazar el ingreso al parador (aunque no esté escrito en su reglamento).

El trabajo que presupone la obtención de las entrevistas en Desarrollo Social, la búsqueda de los papeles y certificados que deben solicitarse en otras instituciones, sumado a los posibles cambios en la organización y reglamentos de los programas, es sentido como una falta de respeto, una instancia tediosa difícil de soportar. Emiliano relata de la siguiente manera su experiencia con el subsidio habitacional: "después que conseguí el trabajo ya el subsidio no me servía, perdía más en los días de trámites... días que no trabajaba. A parte me forreaban, un día acá, que cobrás la semana que viene, que al final, después pagaban dos meses juntos, pero para averiguar tenía que ir, no te informaban por teléfono", y decidió renunciar al subsidio y cubrir los gastos de alquiler con su salario, aunque fuera muy poco el resto de dinero que le quedara para los gastos del mes.

Las instancias que tal vez podrían interpretarse en tanto propias de una organización burocrática, son vividas como instancias de maltrato dirigidas a ellos particularmente, entendiéndolas como relaciones basadas en la discriminación. Los motivos que convocan a las personas a pasar por ellas provienen de la búsqueda de recursos que permitan la resolución o la atención de necesidades básicas, lo que torna difícil el poder elegir no pasar por ellas, y explica, al menos parcialmente, su enojo y malestar.

El intento por no ingresar a ese circuito ha sido experimentado por algunos de nuestros entrevistados, quienes probaron "salir por propia cuenta", esquivando la ayuda de otro, pero con poco éxito. "Si querés quedarte afuera del circuito igual es difícil... hablamos de comer, de dormir". Aceptar una changa puede traducirse en dejar de comer ese día en un comedor y ganarse la posibilidad de seleccionar la comida del día, elegida, distinta a la comida que se repite todos los días en los comedores. Pero nada más, la changa no ofrece otra cosa. Y sostener un trabajo de tiempo completo, lo que permitiría ir más allá del rebusque que otorga la changa, puede ser incompatible con el sostenimiento del parador debido a los horarios en los que deben hacer la fila para poder ingresar a esas instituciones. El supuesto tiempo libre que podrían dedicar a la búsqueda o al sostén del trabajo, se traduce con la organización de estos servicios en la búsqueda del mejor comedor $\mathrm{y} / \mathrm{o}$ del ingreso a un hogar más conveniente (sea por su ubicación, el clima del hogar, y/o el tiempo que dure la vacante) $)^{14}$. Para circular por la ciudad el dinero es necesario, las idas a Desarrollo Social en búsqueda de los tickets sociales o de un subsidio se tornan forzosas. Allí también pueden conseguir los remedios que necesiten, o los anteojos recetados. Algunos de nuestros entrevistados consiguieron un trabajo de medio tiempo que les permitió compatibilizar su actividad con algunos recursos del circuito y con la estadía en un hogar o un parador, pero el empleo no les permitió salir de la calle, y luego de unos meses lo perdieron.

Es en este contexto en el que viven las personas en situación de calle. A continuación, identificaremos en primer lugar los estigmas asociados a las personas en calle y la forma en que estos no solamente son reproducidos en las relaciones entabladas entre los de afuera de la calle y las personas en calle, sino también entre el mismo grupo clasificado como persona en situación de calle. En segun-

14 Por su parte, y desde otro punto de vista, los profesionales y directivos que trabajan en hogares permanentes (a donde no es necesario hacer una fila para ingresar dado que la vacante es reservada por varios meses o años), afirman que las personas que allí concurren tampoco buscan trabajo en su tiempo libre, que se acostumbraron a la vida en el hogar y se instalaron allí, recorriendo el mismo circuito que los usuarios de paradores. 
do lugar, analizaremos particularmente otras prácticas discriminatorias, vinculadas con la nacionalidad.

\section{De estigmas e injurias}

Nuestros entrevistados al hablar acerca de la mirada que los de afuera de la calle tendrían acerca de ellos, manifestaron mucha molestia por sentirse comparados con vagabundos o linyeras; comparación que no solo los colocaría a todos en una misma bolsa, sino que hablaría de ellos como personas "de un valor humano inferior" (Elias y Scotson, 2000). En sus palabras: "Para ellos somos la lacra de la sociedad". La idea de vagabundo, y su par linyera, está asociada, según nuestros entrevistados, a la mendicidad, a la falta de limpieza, a la drogadicción, el alcoholismo, la delincuencia y la locura. Todos ellos atributos profundamente desacreditadores, o estigmas: rasgos que se imponen por la fuerza a nuestra atención y que nos llevan a alejarnos de las personas que los portan, anulando el llamado que podrían hacer los restantes atributos (Goffman, 2003:15). Encontramos en estos atributos estigmatizantes, un rasgo en común, pues todos se vinculan con la falta de cumplimiento de normas, convenciones sociales y leyes, que conllevan cierto peligro y alertarían a las personas del otro lado de la calle que podrían tomar cierto cuidado. $\mathrm{El}$ cargar con estos estigmas traería como consecuencia el padecimiento de prácticas discriminatorias que residen en la negación del derecho a ser diferente y además en colocar la diversidad dentro de escalas sociales jerarquizadas que se estructuran sobre lo legítimo/ilegítimo, bueno/malo, igualdad/desigualdad (Margulis, 1999:45). Estas prácticas colaboran a quebrantar la solidaridad entre el grupo incluido en la misma clasificación y condicionado a llevar adelante una vida que no se caracteriza por tener precisamente las mejores condiciones.

Los relatos que escuché, hablan del malestar que les genera ver a las demás personas cruzarse de vereda ante su presencia, o caras de desagrado o desprecio al pasar cerca de ellos. Marta, una señora que luego de estar tres días en la calle ingresó a un hogar del GCBA, me contó: "es muy pesada la mochila que cargamos los que estamos en situación de calle, yo estuve tres días en la calle con mis hijos y mi nieto, y no sabés cómo sentís las miradas y el prejuicio de la gente". Un concurrente a un parador me dijo sin titubeos: "la sociedad nos mira con asco". La mirada estigmatizante no es un plus que viene a sumarse a la realidad de marginación que sufren, sino un elemento que constituye esa realidad produciendo la desmoralización de las personas (Auyero, 2001).

Particularmente la noción de vagabundo actúa como una injuria al asignarle a las personas una determinada posición social. "La injuria, es un acto del lenguaje -o una serie repetida de actos- por el cual se asigna a su destinatario un lugar determinado en el mundo... La injuria me dice lo que soy en la misma medida que me hacer ser lo que soy" (Eribon, 2001: 31). Y de esta forma no solo moldea las relaciones con los demás, sino que perfila la personalidad, la subjetividad, el ser mismo del individuo (ídem).

Marta también se refirió a la campaña de "Jugá Limpio" impulsada por la actual gestión del GCBA (Macri). En el marco de un proceso de encarecimiento del suelo urbano y de segregación socioespacial de las personas (Di Virgilio y Rodríguez, 2007), producido en un contexto político en el cual bajo el eufemismo de "recuperación de espacios públicos", el GCBA expulsa con violencia a las personas en calle ${ }^{15}$ Marta significó a la campaña como un prejuicio hacia ellos, sintiéndose culpabilizada y responsabilizada de ensuciar la ciudad. Sostuvo que los perjudica, "porque la gente cree que es la gente en situación de calle la que ensucia, pero no somos nosotros, todos hacemos la calle, desde el que fuma y tira el cigarrillo. O los cartoneros, ellos no están en situación de calle, y cuando juntan la basura, está bien, reciclan, pero dejan todo hecho una mugre, es un desastre". En respuesta a esta situación, y junto con sus compañeros del merendero al

Por medio del Decreto 1232/08 el GCBA creó la Unidad de Control del Espacio Público (UCEP), que "oficia en la práctica como una patota que desaloja por la fuerza a indigentes que viven en parques, plazas y edificios de la Capital Federal" (Página 12, 8/3/09). En la oficina de Seguridad Urbana de la Defensoría del Pueblo hay cinco actuaciones de casos donde constan agresiones del $2008(5946,5955,6179,7187$ y 7267) y este año se agregó una sexta, sumada a una denuncia penal contra el Jefe de Gobierno, M. Macri, por parte de la diputada Liliana Parada. Más adelante ampliaremos este tema. 
que asiste, están armando una página web donde plasmar lo que piensan y poder responder a este prejuicio. La consigna va a ser algo así como "todos somos la calle", indicando que todos usamos las calles de la ciudad y al hacerlo las ensuciamos. Su objetivo es evitar que la culpa sea depositada en la gente que está en la calle. En este sentido, Elías menciona que los grupos establecidos se enorgullecen de ser más limpios y agrega que "el sentimiento difundido de que el contacto con miembros de los grupos outsiders contamina, observado en los grupos establecidos, se refiere a la contaminación por la anomia y por la suciedad, mezcladas en una sola y misma cosa" (2000: 29).

El aseo del lugar en donde "paran" así como las marcas corporales (como la ropa, el corte de cabello) pueden llegar a ser aspectos de sumo cuidado por las personas que están en calle, intentando no ser reconocidos por los demás como vagabundos. Al hacerlo, pueden disimular su condición injuriante y pasar al resto de la sociedad, evitando las miradas dolorosas. Sin embargo, el saber que "cargan", como describió Marta, con esa condición injuriante sigue presente, porque "la nominación produce una toma de conciencia de uno mismo como 'otro' que los demás transforman en objeto" (Eribon, 2001:30). Lo que se agrava aún más si consideramos que quienes injurian, están posicionados en un lugar de poder con el que pueden herir y avergonzar.

Sin necesidad de que haya alguien mirando, siendo testigo de la situación, la vergüenza se hace presente. Luis me contó que la primera vez que metió la mano en la basura buscando algo, lo hizo en una calle oscura y solitaria. Sin embargo, se apuró por hacerlo rápido y salir del lugar. Es que las ideas relativas a lo que está bien, lo que está mal o lo que es vergonzoso son compartidas por todos nosotros, los que formamos parte de la misma sociedad. Luis no necesitaba de una mirada externa que le indicara que era un 'otro' dife- rente al buscar algo en la basura. Esa mirada ya estaba dentro suyo, era él mismo el que reconocía su lugar como lugar vergonzante. Así lo explicaría un concurrente a uno de los paradores del GCBA: "Yo sé cómo me ve la gente, si yo también estuve del otro lado de la calle y miraba de la misma forma, o incluso ni los miraba... que no sé qué es peor...". La socialización realizada del otro lado de la calle otorga los elementos para interpretar el "lado de la calle", al cual quizás no se habían imaginado que irían algún día. Pero a la inversa, hay quienes sostienen que "Muchas veces nosotros somos invisibles" o "la gente pasa y ni te ve... es como que no existimos".

Vagabundos, crotos, linyeras, pordioseros, son términos injuriantes para los beneficiarios del GCBA. El término croto surgió a principios de siglo $X X$, a partir de una ley cuyo proyecto fue presentado alrededor de 1920 por el gobernador de la Provincia de Buenos Aires, José Camilo Crotto. A partir de ella, los vagabundos pudieron viajar en los trenes de carga ya no en forma clandestina, sino libre y gratuitamente. Hay entonces un lenguaje, que al menos desde 1920 los precede a los hoy llamados "personas en situación de calle". El mundo de injurias, según Eribon (2001), existe antes que ellos y se apodera de ellos antes incluso de que puedan saber lo que son; porque el ser social de los individuos guarda relación con la posibilidad de ser el objeto de la palabra del otro, incluso antes de que sea expresada efectivamente. "No se existe porque se es reconocido, sino porque se es reconocible" (Butler, 1997. Citado por Eribon, 2001:85).

Los signos reconocibles, marcadores físicos y culturales, son atendidos en tantos puntos de identificación que podrían asociarlos a los vagabundos. De ahí el empeño en no tenerlos y en reafirmarse a sí mismos en la diferencia -traducida en desigualdad- con sus compañeros de albergues ${ }^{16}$. Así, construyen su identidad por oposición, distanciándose de

Los signos reconocibles pueden ser una parte fundamental de las prácticas alternativas generadoras de ingresos (Bourgois, 2003). Alberto, un señor de 82 años, contaba con un único ingreso proveniente de una pensión asistencial, ingreso que él incrementaba pidiendo dinero en la calle. Se sentaba en lo que él denominaba su parada y explotaba estos signos exteriores de los que otros se molestaban. Para él, mantenerse limpio, tener su cabello prolijo y vestir ropa en buen estado, obstaculizaba la forma en la que lograba tener un plus de dinero. A la inversa, para otras prácticas alternativas generadoras de ingresos, los signos reconocibles pueden ser obstaculizadores, como en el caso de la venta ambulante, de quien contrae matrimonio con algún/a inmigrante que requiere la nacionalidad, los llamados "arbolitos" o quien trabaja en el mercado "trucho" de duplicación o construcción de documentos nacionales de identidad. En estos casos, encuentran conveniente que la apariencia física los aleje (al menos imaginariamente) de la calle. 
sus compañeros de desgracia, a quienes califican de linyeras. "Croto es el que quiere. Escuchame, si tenés piojos te los sacás, si ves el bicho caminando. No se los sacan porque no quieren", me dijo una persona que asistía a un parador, explicando por qué él no era croto y otros sí. A su vez, justificaba que a esas personas (los crotos) no se las debería dejar ingresar a los paradores porque podrían contagiarlos.

De esta forma, las personas en calle no solo se sienten posicionadas en un lugar estigmatizante frente a la sociedad en general, sino que además reproducen los estigmas al aplicarlos a otros en su misma situación intentando diferenciarse del colectivo al que no sienten pertenecer. Eduardo lo explica diciendo que "La gente de la calle está muy mezclada, hay gente que se quedó sin trabajo, que quedó sin casa, y que va al hogar por equis problema, por ejemplo porque se separó de la mujer y se quedó sin nada. Pero está la otra parte, delictiva, la parte criminal, de drogas, la parte de delincuencia que se mezcla con esta gente. Gente con poco pedigrí, por decir así. Entonces hay un choque de culturas. Esto lo pude ver en todos los hogares, públicos y privados, y también en los paradores".

Las prácticas de diferenciación pueden llegar hasta el punto de sostener un discurso como si estuvieran del otro lado de la calle. Ingresando a un parador del GCBA, en épocas de elecciones de la ciudad, un beneficiario me comentó "Yo voy a votar a Macri, ojalá que gane y cierre todos estos lugares de mierda". En ese mismo lugar, me enteré que habían asesinado a un señor que asistía al parador. Al conversar acerca de ello con un concurrente del mismo establecimiento, me dijo: "Uno menos, ojalá que los maten a todos". Y es que la frase que escuché reiteradamente, "Yo no soy como estos, yo no quiero estar acá" o "Yo sí quiero trabajar" es tan firmemente sentida por cada uno al punto de su convencimiento. $Y$ en cada una de estas frases podemos entrever no solo una diferenciación, una estrategia de desplazamiento del estigma (Goffman,1963), sino la reproducción de los estigmas mismos y los discursos discriminatorios que anulan la humanidad de quienes podrían ser sus compañeros. En otros términos, pero con una sonrisa irónica, Ricardo me explicó su forma de ver las cosas: "yo no discrimino a nadie, los odio a todos por igual". Y aunque las prácticas solidarias también están presentes entre ellos, como sostiene P. Levi "todo esto está lejos del cuadro que suele imaginarse de los oprimidos que se unen, si no para resistir, cuando menos para sobrellevar algo" (1987:156).

\section{La nacionalidad construida como estigma}

Si bien el estigma funciona como una injuria moldeando no solo la personalidad y la subjetividad, sino también las relaciones al interior del grupo clasificado como persona en situación de calle, las prácticas de diferenciación que observamos al interior del grupo pueden ser dejadas a un lado cuando un grupo, construido como "otro", aparece como posible responsable del desempleo y la situación de calle.

La falta de trabajo o la dificultad para conseguir la inclusión en un plan social, son explicadas por nuestros entrevistados aludiendo a la responsabilidad de los "bolivianos que se regalan y trabajan por poca plata”, que "le sacan el trabajo a un argentino", o a la irresponsabilidad del GCBA que otorga los escasos planes sociales a peruanos y bolivianos, sin privilegiar la atención de los compatriotas. Argentinos versus inmigrantes pareciera ser la fórmula vinculada a la experiencia del desempleo y a la dificultad de conseguir la inclusión en algún plan social. "Los grupos de inmigrantes están convirtiéndose crecientemente en chivos expiatorios de la frustración que la marginación produce" (Auyero, 2001:88). Pero precisemos que no todos los inmigrantes son catalogados de la misma forma. Podemos inferir de los relatos de nuestros entrevistados, diferentes categorías de "extranjeridad": particularmente, como veremos en la experiencia analizada, son los peruanos y bolivianos los chivos expiatorios.

En un taller dictado en octubre de en el año 2008 en un parador del GCBA, 15 personas discutían junto con representantes de Proyecto 7 la dificultad de vivir en la calle. "Habría que ir a Desarrollo Social y pedir que levanten la mano los argentinos, a ver cuántos hay", fue lo que dijo un participante, luego de que otro reflexionara acerca del subsidio habitacional: “Pero el subsidio, ayudan más a los extranje. 
ros que a los propios argentinos... a un bolita, un peruano les dan subsidios. ¡Y es más! ¡Al toque! Pero a uno que realmente lo necesita, a un argentino... Primero están los bolitas y los peruanos y después los que están acá. Que vayan a su país a pedir subsidio". Ante el rechazo sufrido por esta persona, sin posibilidad de acceder al subsidio, su reflexión apuntaba a otros, también discriminados y posicionados en un lugar desposeído. Sucede una situación similar a la que Wacquant señala en la cité francesa, donde "los residentes suelen insistir que solo están allí 'por accidente' y se quejan del dispendio de recursos públicos asignados a quienes, 'al contrario de ellos', no necesitan una genuina asistencia” (2001:143).

Sin embargo, esta experiencia también nos introduce en otro aspecto que es justo señalar. Proyecto 7 es uno de los ejemplos que demuestra que las personas en calle también pueden agruparse y movilizarse en búsqueda de mejores condiciones de vida. Es una asociación civil que nuclea a personas que están y que estuvieron en la calle. El taller mencionado en el párrafo anterior fue organizado por integrantes de Proyecto 7 y por profesionales del parador Bepo Ghezzi del GCBA, gobierno ante el cual Proyecto 7 se enfrenta por medio de movilizaciones, huelgas de hambre y a donde ha presentado proyectos de ley que apuntan a dignificar las condiciones de vida de las personas en situación de calle. En ese taller, Proyecto 7 presentó un documental de su autoría y convocó a los beneficiarios a sumarse a su proyecto y formar parte del grupo.

En otro espacio grupal, Ricardo retomó las diferencias según nacionalidad. Para él "los que vivimos y somos de acá tendríamos que tener derecho. Por qué privilegian a los extranjeros?" Según Ricardo, "ningún bolita o peruano está en la calle como nosotros... ellos ocupan casas o edificios, o se van a las villas, entonces ¿por qué tienen tantos subsidios y beneficios? El Estado los privilegia y no nos tiene en cuenta a nosotros".

Si bien la otredad es una condición común a partir de la cual el "nosotros" se diferencia y logra la construcción de la identidad social; la distancia social y simbólica que nos separa de "otro" puede ser mayor o menor y variar en su carga afectiva y valorativa (Mar- gulis, 1999:44). En los casos reseñados, la distancia social, de clase, no necesariamente es amplia; pero la distancia simbólica, así como la carga afectiva y valorativa es profunda y traduce la diferencia en desigualdad. Constituye otra estrategia de distinción, en la cual el colectivo de "vagabundos" del cual se distinguen, fue dejado a un lado para diferenciarse en tanto un "nosotros" de un "otro" delimitado por la nacionalidad, que no viviría en la calle, sino en villas o edificios ocupados. Como si solo pudieran ganar en valor, devaluando a quienes tienen cerca y con quienes se relacionan. La diferencia de nacionalidad no explica lo sucedido en el grupo. Fue la necesidad de posicionarse en un lugar de poder diferencial ante los otros y considerarse "mejores" que ellos, lo que impulsó ese discurso. Encontraron en el "ser argentino" un recurso que los dotó de un plus de poder frente a otros estigmatizados de quienes intentaron diferenciarse.

Un proyecto de "integración": el coro de ensambles vocales

En el 2008, las empleadas que conforman el Área de Revinculación Sociocultural y Laboral (dos terapistas ocupacionales y una estudiante de música) recibieron una nueva directiva: conformar un coro de ensambles vocales integrado por beneficiarios de hogares y paradores del GCBA. Durante el mes de agosto realizaron la convocatoria a través de los hogares y paradores del GCBA. A los beneficiarios que asistieran al $75 \%$ de los ensayos, les otorgarían una beca, en concepto de viáticos y remuneración, de 245 pesos mensuales, durante el tiempo que llevara conformar el coro. Una vez terminada esta etapa inicial, recibirían indumentaria profesional artística y una salida laboral, que consistiría en la asistencia a las presentaciones del coro. Hasta que estuvieran asignadas las becas, una camioneta del BAP estaría a disposición para llevar y traer a las personas al Centro Cultural Plaza Defensa, donde se realizarían la actividad.

Un mes después, en septiembre, comenzaron los ensayos coordinados por tres profesores de canto, cantantes de ópera del Teatro Colón, y en dos oportunidades asistió también el director del coro, que también era el director del coro del Teatro Colón. 
La propuesta fue inicialmente muy bien recibida por los participantes, algunos interesados con la actividad, otros con la posibilidad de obtener una beca y una salida laboral, otros con ambas cosas. Pero ya en el primer mes comenzaron algunas dificultades. Recordemos que la falta de cumplimiento de programas del gobierno es sentida por los "beneficiarios" como una práctica discriminatoria. El incumplimiento de la entrega de recursos en tiempo y forma, renueva sensaciones de rechazo, de negación, de frustración que se suma a anteriores expectativas no cumplidas, y a la odiada incertidumbre que acrecienta a la ya conocida incertidumbre sobre cómo podrán rebuscárselas al día siguiente.

En esta experiencia, las dificultades fueron varias: la camioneta del BAP no cumplió con lo previsto y llegar al Centro Cultural fue muy difícil para algunos. El cobro de la beca no fue al término del primer mes como esperaban. Algunos participantes al llegar a los paradores luego de haber ensayado, se encontraron con que ya estaban cubiertos los cupos de las instituciones y algunas noches se quedaron en la calle, situación que en las primeras semanas se revirtió y los paradores comenzaron a reservar las vacantes para quienes asistieran al coro.

Durante una entrevista, Jorge me leyó el volante que describía los beneficios que recibirían por la participación en el proyecto, lo llevaba guardado como un documento. Ya habían pasado dos meses de la conformación del coro y todavía no habían cobrado. "Mirá, qué dice acá, yo cumplí con mi parte pero ellos no... Al final somos los boludos. Ellos sacan votos, muestran lo que hacen y nadie piensa en nosotros. No le importamos a nadie". Pasados ya tres meses de asistencia al coro, Juan (como todo el grupo) todavía no había cobrado: "Estoy cansado de ilusionarme que hay una salida, otra vez pensé que acá la iba a encontrar, y me vuelvo a encontrar con lo mismo. Porque cuando vos llegás a un punto y decís 'cómo salgo?' y creés que la encontrás pero no, y otra vez, pero no... ¿después cómo seguís?".
El proyecto duró cuatro meses (septiembre a diciembre de 2008). Cerca de 40 personas participaron. Para asistir y ante la ausencia de la camioneta del BAP, cada uno resolvió como pudo la forma de viajar, utilizando un pase de transporte para personas con discapacidad "trucho", pagando el boleto, caminando o en bicicleta. A pesar de los problemas organizativos y la falta de cumplimiento en lo que el gobierno había prometido, Tulio, como otros también, decidió seguir asistiendo hasta el final. Estaba muy contento con la actividad, en sus palabras: "la parte técnica es muy buena, los profesores son encantadores. Me siento muy bien en ese lugar". Por su parte, la madre de Jorge había sido cantante del Colón. Era muy poco lo que él sabía de ella. Encontró entonces la oportunidad de descubrir si alguna huella de su madre había quedado en él. Tocando su garganta me dijo " $A$ ver si acá hay algo de ella." Habló de su madre con el director, quien le prometió buscar en los archivos si tenían alguna fotografía de su madre cantando.

En esa actividad, también evitaban hacer la fila para ingresar a los paradores ${ }^{17}$. Los ensayos del coro eran martes y jueves de 17 a 19. Quienes asistieron tuvieron esos días la cama reservada en su lugar de alojamiento. Matías lo expresó así: "En realidad yo prefiero venir acá antes que estar en la fila. En la fila no me aguanto a la gente, te soy sincero, se quejan todo el tiempo. No tengo ganas de escuchar los problemas de los demás." Tulio me dijo que si yo prestaba atención, iba a darme cuenta de que en el centro cultural donde ensayaban la gente estaba hablando de música, de los profesores que eran muy divertidos, de cómo estaban progresando o de qué podrían hacer, del debut del coro o practicando canciones. En contraste diferencia, en la fila del parador la gente solía quejarse y hablar de sus problemas, quizás buscando a alguien que tuviera alguna respuesta o idea acerca de cómo resolverlos. En el coro la gente no se quejaba tanto. Sí discutían las dificultades de la camioneta que no los pasaba a buscar, los viáticos que no les pagaban y algún que otro tema difícil del parador, pero la pasaban bien.

Como en los paradores la vacante es diaria, todos los días ingresa un máximo determinado de personas que varía según la cantidad de vacantes que tengan (70 en el parador Bepo, 150 en el Retiro y 35 en el Villaflor). Para segurar su ingreso, las personas hacen una fila desde varias horas antes de la apertura institucional. 
Esperaban el "debut artístico" del coro pero fue suspendido. $Y$ el último ensayo del año los encontró con las puertas cerradas. El centro cultural donde se realizaban los ensayos no tenía la indicación de reservar el lugar para ellos. Todos quedaron del lado de afuera, junto con los profesores de canto que sin información acerca del aspecto organizativo, no podían hacer más que exteriorizar su indignación: "Para mí esto es una falta de respeto, es inaudito que no venga nadie a poner la cara, una falta de respeto a mi trabajo, a mi tiempo, pero para ellos... para ellos esto es humillante". Además, ninguno sabía qué sucedería el próximo año, estando en ese momento a mediados de diciembre. Nuevamente la incertidumbre tan nombrada se hizo presente. Luis ese día estaba alcoholizado, tenía su cara hinchada y colorada y se tambaleaba al andar. Yo sabía que tenía problemas de alcoholismo, pero estaba sorprendida de lo bien que habría estado manejando ese problema, porque si bien podría haber tomado en esos tres meses, a ningún ensayo había concurrido alcoholizado. Antes de que me fuera me dijo "No ves Marianita, esto grabalo, anotalo (y hacía un gesto de mano como escribiendo en el aire), que quede, viste como nos usan? No valemos nada, por eso, a quién le importa, juegan con nosotros".

Esta es una de las manifestaciones en que Desarrollo Social se vincula con las personas, quienes recibieron un recordatorio no muy metafórico de su lugar de excluidos. Pero los vínculos entablados entre los profesores de canto y sus alumnos, también nos muestran otra de las caras de esas manifestaciones. "Vos tenés que dedicarte a cantar y dejarte de pedir plata. Tenés una voz excepcional, tenés que dejarte de joder, ir a los bares, a los restaurantes y cantar para la gente" le dijo a Luis uno de los profesores, como en un fuerte reto amoroso donde había expectativa de que podía porque era bueno cantando, y también una disputa contra el saber de que con la voz no alcanza, que no es suficiente. Luis (que estaba alcoholizado) lo escuchaba con la cabeza gacha e inclinada un poco a su derecha, mirando hacia arriba con ojos entreabiertos como espiando. Parecía un padre retando a su hijo querido. La sensación de ternura que me inspiró esa escena me duró poco porque Ricardo, que estaba parado a mi lado, me dijo algo así como "pero si este a los bares a lo sumo solo puede cantarle al mozo '¡otra ronda!'”. En mi registro de campo de ese último día, el $16 / 12 / 08$, escribí "Creo que la risa nos acerca a la salud, y en ese mundo el humor ácido ayuda a reírse, a descargar tensiones o al menos a sobrellevar situaciones difíciles".

Por su parte, Ricardo, que tenía una pelota de fútbol que había encontrado ese mismo día, agregó riendo: "qué cagada, ahora no voy a poder hacer el paro activo que tenía pensado. Iba a quedarme acá afuera jugando a la pelota, porque no nos pagan, pero ahora ¿cómo me quejo? No me dejan manifestarme". Tanto él como Emiliano estaban elaborando el fin de una de sus bromas. Ya no iban a poder seguir firmando en la planilla de asistencia nombres falsos como Johny Tolengo, Elvio Lento, Elsa Tiro o Armando Bardo. La encargada de pasar la asistencia y construir las estadísticas se había enojado bastante con ellos, cuando después de varias semanas de encontrarse con disparidades de nombres que no se correspondían con los inscriptos, se dio cuenta de que "El violento" o "El sátiro" eran los nombres (demasiado raros) que le estaban generando los problemas. Los responsables, al darse cuenta de que habían sido descubiertos, se acercaron a las organizadoras de la actividad (empleadas de Desarrollo Social) quienes mostraban en sus expresiones que estaban bastante enojadas. "Pero decime si no te reíste cuando pasabas la lista" le dijo Emiliano a quien se encargaba de la asistencia. "Con Johny Tolengo te tenés que haber dado cuenta." De alguna manera se hicieron cargo de la broma intentando distender a las organizadoras y entre risas terminó el episodio.

\section{Acerca de la segregación espacial}

Las prácticas discriminatorias también pueden manifestarse de otras formas a las aludidas hasta ahora. La ubicación que el GCBA ha seleccionado para construir las instituciones de albergue coincide en que sean zonas periféricas, dividiendo a la ciudad en espacios para unos y otros, y afectando los itinerarios cotidianos. En el caso de los paradores, uno se ubica en la zona de Retiro, en el ingreso de la villa del mismo nombre, oculto entonces para los "porteños". El otro, está al lado de otra villa, llamada Zabaleta, que se une con 
la de Barracas y Lugano, esta vez al sur de la ciudad, en el barrio de Parque Patricios. A esa zona de la ciudad, las personas cuentan que no solían ir hasta que armaron el parador, porque no hay comedores, merenderos, u otras instituciones que los convocaran, así como tampoco hay circulación de gente, hay muy poca actividad comercial y es de difícil acceso, "En ese barrio no había nada". Pareciera ser en este sentido, y así como describe Wacquant al hipergetto, ya no "un reservorio de trabajadores industriales disponibles, sino un mero lugar de desecho para las numerosas categorías de las cuales la sociedad circundante no hace uso político o económico alguno" (2001:110).

Así como el gobierno ha creado espacios para personas en calle en los límites de la ciudad, colaborando en procesos de desplazamiento indirecto ${ }^{18}$ (Herzer, 2008) de parte de la población, también se dispuso en este último año a "limpiar" la ciudad, lo que hablaría ya de un desplazamiento directo (ídem). "Desintrusar" es la forma en que llaman, desde el GCBA, a los operativos de "limpieza" en los que sacan, a veces echan con violencia, a los "intrusos" de los espacios públicos. Es una nueva forma en que el Estado interviene sobre unas vidas que se vuelven nuda vida, "es decir, vidas sometidas al arbitrio de una instancia superior que puede determinar el sentido de sus existencias o, más grave aún, de sus muertes" (Forster, 2001:90). "Recuperar" los espacios de la ciudad ha sido uno de los objetivos del Ministerio de Ambiente y Espacio Público del GCBA. En el año 2008 llevaron a cabo 382 operativos y lograron que de 160 espacios públicos "intrusados" quedaran 65; además casi cien plazas donde vivía parte de las 700 personas en calle han sido "limpiadas" (Diario Perfil, 30/11/08). En ese mismo diario explican que "se trata de una 'fuerza para tareas especiales' con una agenda bien clara para 'limpiar de intrusos los lugares públicos, en nombre de la ley', tal como reconocen con soltura ellos mismos". Algunos de esos operativos han incluido situaciones de violencia en los cuales las pertenencias de las personas fueron tiradas a camiones de basura y ellos agredidos física y moralmente. A la violencia policial se suma ahora la violencia de esta nueva fuerza para tareas especiales que ha creado la Unidad de Control del Espacio Público (UCEP) por medio del decreto 1232/8. Apelando a la ley y en nombre de ella, el Estado reprime. Con lo cual, la violencia continúa aún después de esos operativos, cuando no encuentran institución donde radicar la denuncia y/o donde ser escuchados, atendidos y reconocidos como víctimas "legítimas". Sin embargo, a los dos meses de la creación de esa fuerza, tres denuncias habían sido radicadas en la Defensoría del Pueblo de la Ciudad de Buenos Aires, y para marzo de este año ya eran seis, a las que se suma una denuncia penal contra el Jefe de Gobierno (Página 12, 8/3/09). Podemos encontrar en estas situaciones de violencia una de las manifestaciones en las cuales la vida humana se incluye en el orden jurídico bajo la forma de exclusión (Forster, 2001).

Ambas formas (sea por medio del desplazamiento a partir de la oferta de servicios que cubran necesidades básicas, como por medio de sacar violentamente a alguien de su "parada") constituyen prácticas de segregación espacial. Las personas en situación de calle, sean bolivianas, peruanas o provincianas, pero en todo caso no vecinas de la ciudad, son así extranjerizadas y construidas como los "intrusos". Este discurso dominante se filtra en el entramado simbólico de la sociedad y se transforma en un sentido común que no se restringe al punto de vista oficial.

\section{Palabras finales}

La imagen de una ciudad dual y fracturada es fructífera para describir los efectos que genera la polarización económica en la geografía y ecología urbanas (Wacquant, 2001). Nuevas desigualdades se generaron con la eliminación de miles de puestos de trabajo y la retirada del Estado en su función de welfare, incrementando su función punitiva y represiva en los últimos años. Particularmente en este trabajo nos propusimos reseñar un caso particular de pobreza urbana que refiere a la desigualdad extrema, en el que las lla-

Si bien la definición que Herzer aporta a la idea de desplazamiento hace referencia a "gente que es forzada a dejar sus viviendas" (2008:27), es instrumental su uso en esta oportunidad, aunque nuestro caso se refiera a gente sin vivienda, dado que las personas en calle consideran al barrio por el que transitan como su lugar de pertenencia. La instauración de albergues en barrios no transitados por ellos, los obliga en forma indirecta a desplazarse hacia ellos. 
madas necesidades básicas se transforman en un problema a ser resuelto. Como vimos, son diversas las formas en que las personas en situación de calle enfrentan su día a día, construyendo una rutina que supone la asistencia a instituciones donde poder resolver algunas de estas necesidades. En estas instituciones las personas en calle deberán relacionarse con la persona a cargo del ingreso, y en algunos casos demostrar el vínculo pasado con otros profesionales que - por medio de certificados, firmas y sellos en hojas membretadas- dejarán constancia de la veracidad del discurso que lo constituye en "merecedor" del servicio, en un demandante "legítimo". Recordemos también los contactos que algunos de nuestros entrevistados tuvieron con Desarrollo Social, en el intento de hacer valer algunos de sus derechos. Es decir, que la resolución de algunas necesidades implica, necesariamente, el vincularse con otro; y ese vínculo entablado, atravesado por el estigma y la injuria, conforma la vida en la calle. Por su parte, las personas responden a esta situación, vinculándose con los estigmas asociados a la categoría de vagabundo también de variadas formas. El estigma, actuando como una injuria, fue un tema central no solamente porque forma parte de las relaciones discriminatorias construidas por las personas en calle, sino porque es un elemento que las constituye, colaborando en la profundización de procesos discriminatorios.

En la experiencia analizada encontramos a los miembros de un grupo outsider, sintiéndose estigmatizado por los miembros de otro, no por sus cualidades individuales como personas, sino por la pertenencia de ellas a un grupo colectivamente considerado diferente e inferior. De la misma manera, el grupo estigmatizado se posicionó como establecido frente a otro, inmigrante, operando entonces un mecanismo similar de diferenciación y discriminación. A su vez, entre el grupo outsider observamos estrategias de diferenciación entre ellos para evitar sentirse parte del colectivo (vagabundo) al cual no sienten ni quieren pertenecer.

Pero además, como señalamos en la introducción, si bien el objetivo de este trabajo ha sido reseñar las maneras en que las prácticas discriminatorias se hacen presentes en la vida cotidiana de las personas que están en ca- lle y que son albergadas por el GCBA, también debemos mencionar que pudimos observar prácticas solidarias, de cooperación y estrategias de resistencia y de lucha. Hubo quienes pudieron reírse en situaciones difíciles, fuimos testigos de bromas entre beneficiarios y empleados de Desarrollo Social, quienes también demostraron poder relacionarse de manera respetuosa y cálida (recordemos al profesor de canto conversando con Luis, o la encargada de la asistencia aceptando una broma que entorpeció su trabajo durante semanas). A su vez, en Desarrollo Social, y a pesar de la organización de esta institución, las personas en calle logran la resolución de algunas de sus necesidades, imperiosas de atender. El proyecto de conformación de un coro fue muy bien recibido por sus integrantes y sus ensayos fueron fuente de goce disfrute, mientras duraron. Por otra parte, proyectos de ley, movilizaciones, huelgas de hambre, "frazadazos", denuncias penales, amparos judiciales y creación de documentales donde dar a conocer y hacer visible el problema de las personas en calle, son algunas de las acciones que en la lucha por la inclusión y mejores condiciones de vida vienen realizando personas en situación de calle organizadas en movimientos y por las ONG.

\section{Bibliografía}

AUYERO, J. (2001). La política de los pobres. Las prácticas clientelistas del peronismo. Ed. Manantial. Buenos Aires.

BOURGOIS, P. (2003). In search of respect. Selling crack in El Barrio. Cambridge University Press. Nueva York.

ELIAS, N. y SCOTSON, J. (2000). Os Establecidos e os Outsiders. Sociologia das relações de poder a partir de uma pequena comunidade. Jorge Zahar, editor. Río de Janeiro.

DI VIRGILIO, M. M. y RODRÍGUEZ, M. C. (2007). Políticas del hábitat, desigualdad y procesos de segregación socioespacial en el Área Metropolitana de Buenos Aires. AEU-IIGG / FSOC-UBA.

ERIBON, D. (2001). Reflexiones sobre la cuestión gay. Ed. Anagrama. Barcelona.

FORSTER, R. (2001). "La política como barbarie: una lectura del homo sacer de Girorgio Agamben". En Revista Sociedad. Facultad de Ciencias Sociales. UBA. № 19. 
GOFFMAN, E. (1963). La presentación de la persona en la vida cotidiana. Ed. Amorrortu. Buenos Aires.

(2003). ESTIGMA. La identidad dete-

riorada. Ed. Amorrortu. Buenos Aires.

HERZER, H. (2008). Con el corazón mirando al sur. Transformaciones en el sur de la ciudad de Buenos Aires. Ed. Espacio. Buenos Aires.

LEVI, P. (2003). Si esto es un hombre. Muchnik Editores. Barcelona.

MARGULIS, M. (1999). "La racialización de las relaciones de clase". En Margulis, Urresti y otros (1999): La segregación negada. Cultura y discriminación social. Ed. Biblos. Buenos Aires.

PENNA, M. 1992. 'O que faz ser nordestito'. Identidades sociais, interesses e o 'escandalo'. Erundina. Cortez Editora. São Paulo.

REPETTO, M. S. y MALANCA, P. (2003) Personas en situación de calle en la Ciudad de Buenos Aires: el abordaje desde un programa social de emergencias. Mimeo. Buenos Aires.
RODRÍGUEZ, M. C. (2006). "Tiempo de caracoles... Autogestión, políticas del hábitat y transformación social". Tesis Doctoral en Ciencias Sociales. UBA.

WACQUANT, L. (2001). Parias urbanos marginalidad en la ciudad a comienzos del milenio. Ed. Manantial. Buenos Aires.

\section{Otros documentos}

DECRETO 1232/8. Boletín Oficial de la Ciudad de Buenos Aires № 3045. 29/10/2008.

DECRETO 690/006. Boletín Oficial de la Ciudad de Buenos Aires № 2463. 21/06/2006.

DECRETO $N^{\circ}$ 2.018. Boletín Oficial de la Ciudad de Buenos Aires N 803; 22/10/1999.

DECRETO No 607/997. Boletín Oficial de la Ciudad de Buenos Aires N² 213; 06/06/1997.

DIARIO PERFIL 30/11/2008.

DIARIO PÁGINA 12, 08/03/2009 